\title{
Cancer-related Fatigue of Breast Cancer Survivors: Qualitative Research
}

\author{
Son, Haeng-Mi' $\cdot$ Park, Eun Young ${ }^{2} \cdot$ Kim, Eun-Jeong ${ }^{3}$ \\ ${ }^{1}$ Department of Nursing, University of Ulsan, Ulsan; ${ }^{2}$ College of Nursing, Gachon University, Incheon; College of Nursing, Dong-A University, Busan, Korea
}

Purpose: Cancer-related fatigue (CRF) is an important health concern among breast cancer survivors. However, CRF is apt to be dismissed as a minor discomfort by medical professionals. This study aimed to understand the experience of CRF in breast cancer survivors. Methods: We conducted a qualitative study using in-depth interviews and thematic analysis. The 14 participants were over the age of 40, complained of fatigue, and had been battling breast cancer for at least eight months to up to 16 years. Results: The analysis revealed four themes: traces of fighting cancer, inseparable part of the self, difficulty in daily life, and the body's signals for care. Chronic fatigue initially disrupted the daily lives of the participants. As time passed, fatigue made it difficult for patients to fulfill their roles within their families, and gradually alienated friends and neighbors. Nevertheless, they tried to overcome the symptoms of fatigue by responding sensitively to the warning signs or changes in their bodies. Conclusion: Breast cancer survivors often worry about relapse due to persistent fatigue after treatment completion. Therefore, the results of this study may be useful in developing strategies tailored for managing CRF using a multifaceted approach.

Key Words: Breast neoplasms, Fatigue, Cancer survivors, Qualitative research

\section{INTRODUCTION}

Patients with breast cancer typically experience symptoms, such as weakness, anorexia, nausea, and fatigue in the course of the disease, and of these, fatigue is most commonly reported. ${ }^{1-3)}$ Cancer-related fatigue (CRF) is the most common problem experienced due to the disease itself or its treatment modalities, and is associated with various factors, such as side effects of treatment, loss of appetite, metabolic disorders, physical dysfunction, decreased physical activity, neuromuscular dysfunction, pain, and sleep disorders. ${ }^{4)}$ Unlike general fatigue, patients' with CRF do not recover naturally owing to rest and sleep during the course of the disease. ${ }^{5)}$ In addition, health care professionals tend to neglect patients' complaints of fatigue, which can negatively affect their quality of life. Cancer patients continue to appeal to medical professionals regarding their symptoms of fatigue and pain, but medical professionals do not value the impact of fatigue on their daily lives as compared to pain, thus, underestimating the fatigue

*The authors gratefully acknowledge the patients who participated in this study and the Korea Institute of Oriental Medicine which helped recruit participants.

Address reprint requests to: Park, Eun Young 191 Hambakmoero, Yeonsu-gu, Incheon, Korea Tel:+82-32-820-4603 Fax:82-32-820-4201 E-mail:parkeunyoung@gachon.ac.kr Received:Sep 14, 2020 Revised: Dec 02, 2020 Accepted: Dec 12,2020

This is an Open Access article distributed under the terms of the Creative Commons Attribution NoDerivs License. (http://creativecommons.org/licenses/by-nd/4.0/) If the original work is properly cited and retained without any modification or reproduction, it can be used and re-distributed in any format and medium. experienced by cancer patients. ${ }^{6)}$ Therefore, it is necessary for healthcare professionals to recognize and treat CRF, which is often overlooked in clinical practice, as an important factor in the treatment and care process.

Since the 1980s, various research methods have been applied to understand the concept, mechanism, and contributing factors of CRF. ${ }^{7)}$ Surgery, chemotherapy, radiotherapy, and hormone therapy to treat breast cancer aggravate treatment-related fatigue. ${ }^{1)}$ Moreover, diseaserelated fatigue among patients with breast cancer negatively affects their work, social relationships, mood, and daily life, resulting in a vicious cycle that reduces their health-related quality of life. ${ }^{2)}$ Identifying the symptoms of fatigue in the course of the illness and treatment can lead to early detection and active treatment of stress and burden from fatigue, thereby improving patient experience and treatment outcomes. ${ }^{1)}$

Therefore, effective management and treatment of CRF requires a deeper understanding of the subjective experience of CRF among cancer patients. ${ }^{2,5)}$ Moreover, healthcare professionals tend to treat fatigue as a symptom derived from the treatment process; ${ }^{1.8)}$ therefore, the very complex and subjective fatigue experienced by cancer survivors in their daily lives is difficult to understand.

This study aimed to understand and describe the subjective experience of CRF among breast cancer survivors in-depth. The findings of this study may facilitate the development of effective management strategies and early detection of CRF and everyday life stresses experienced by 
survivors since being diagnosed with breast cancer.

\section{RESEARCH METHODS}

\section{Research Design}

This is a qualitative research employing individual in-depth interviews that delve deeply into the experience of CRF in breast cancer survivors.

\section{Research Participants}

A total of 14 individuals who subjectively complained of fatigue symptoms were included as participants. Of these, 7, 4, and 3 participants were in their 40s, 50s, and 60s, respectively; further, 13 were married while 1 was divorced; and 11 had a religion whereas 3 had no religion. Two participants were metastatic cancer patients; and the duration of the illness of the 14 participants was less than one year, one to three years, three to ten years, and more than ten years for one, eight, four, and one participant(s), respectively. The participants were treated with one or more surgery, radiation therapy, chemotherapy, and hormone therapy; and subjective fatigue, measured by the visual similarity scale, ranged from 2 to 8 points. CRF is a symptom of subjective experience that affects daily life. Participants of various CRF levels were selected to navigate the fatigue experience at different levels(Table 1).

Table 1. Participant Demographics

\begin{tabular}{|c|c|c|c|c|c|c|c|}
\hline No. & $\begin{array}{l}\text { Age } \\
\text { (years) }\end{array}$ & Marital status & Education & Religion & $\begin{array}{l}\text { Period of illness } \\
\text { (months) }\end{array}$ & $\begin{array}{c}\text { Cancer-related } \\
\text { treatment }\end{array}$ & $\begin{array}{l}\text { Fatigue } \\
\text { (VAS) }\end{array}$ \\
\hline 1 & 43 & Married & College & Christianity & 13 & $\begin{array}{l}\text { Surgery } \\
\text { Chemotherapy } \\
\text { Radiotherapy } \\
\text { Hormone therapy }\end{array}$ & 2 \\
\hline 2 & 43 & Married & College & Christianity & 19 & $\begin{array}{l}\text { Surgery } \\
\text { Radiotherapy } \\
\text { Hormone therapy }\end{array}$ & 4 \\
\hline 3 & 66 & Married & Middle school & Buddhism & 8 & Surgery & 3 \\
\hline 4 & 61 & Married & High school & Buddhism & 45 & $\begin{array}{l}\text { Surgery } \\
\text { Chemotherapy } \\
\text { Radiotherapy }\end{array}$ & 4 \\
\hline 5 & 58 & Married & College & & 16 & $\begin{array}{l}\text { Surgery } \\
\text { Chemotherapy } \\
\text { Radiotherapy }\end{array}$ & 3 \\
\hline 6 & 60 & Married & College & Christianity & 26 & $\begin{array}{l}\text { Surgery } \\
\text { Radiotherapy }\end{array}$ & 7 \\
\hline 7 & 44 & Married & High school & No religion & 14 & $\begin{array}{l}\text { Surgery } \\
\text { Radiotherapy }\end{array}$ & 5 \\
\hline 8 & 41 & Married & College & Christianity & 33 & $\begin{array}{l}\text { Surgery } \\
\text { Chemotherapy } \\
\text { Radiotherapy }\end{array}$ & $5 \sim 7$ \\
\hline 9 & 41 & Married & College & No religion & 35 & $\begin{array}{l}\text { Surgery } \\
\text { Chemotherapy }\end{array}$ & 6 \\
\hline 10 & 46 & Married & College & Christianity & 53 & $\begin{array}{l}\text { Surgery } \\
\text { Chemotherapy } \\
\text { Radiotherapy }\end{array}$ & $4 \sim 8$ \\
\hline 11 & 48 & Married & College & Christianity & 35 & $\begin{array}{l}\text { Surgery } \\
\text { Chemotherapy } \\
\text { Radiotherapy }\end{array}$ & $3 \sim 7$ \\
\hline 12 & 59 & Married & College & Buddhism & 192 & $\begin{array}{l}\text { Surgery } \\
\text { Chemotherapy }\end{array}$ & 7 \\
\hline 13 & 53 & Married & College & Buddhism & 72 & $\begin{array}{l}\text { Surgery } \\
\text { Chemotherapy } \\
\text { Radiotherapy }\end{array}$ & 5 \\
\hline 14 & 50 & Divorced & College & Christianity & 76 & $\begin{array}{l}\text { Chemotherapy } \\
\text { Radiotherapy }\end{array}$ & $4 \sim 7$ \\
\hline
\end{tabular}

VAS= visual analogue scale. 


\section{Data Collection}

Data were collected through in-depth interviews conducted by all the researchers from August 10 to November 22, 2017. Interview questions were as follows: what symptoms of fatigue did you experience during or after your cancer treatment?; have you experienced any changes in your daily life due to fatigue? please elaborate; have you experienced changes in family or interpersonal relationships caused by fatigue? please tell me how you responded to these changes; please talk about what you are doing in your daily life to manage your fatigue; and what does the fatigue emerging from cancer mean to you?

Interviews initially began with common daily conversations to make the participants feel at ease and to form a rapport. As the interview progressed, we asked questions specific to the purpose of the study. The interviews, lasting about 1 to 2 hours, were recorded with the consent of the participants, and the reason for recording was explained to the participants in advance. The interviews were conducted at a quiet cafe or a hospital meeting room, as per the convenience of the participants. During the interviews, we participated as active listeners, noting the participants' responses or important clues. Data saturation was reached when no new information could be retrieved from the interviews, and hence, data collection was discontinued. The participants' personal and disease related responses were collected in a self-reported questionnaire that could be completed within 5 minutes.

\section{Data Analysis}

Data analysis was conducted to understand and describe the research phenomena by subjectively interpreting the data through a coding process and theme identification of interview data. Data analysis was conducted using qualitative thematic analysis by Braun and Clarke (2006).9) Individual in-depth interviews were transcribed verbatim by a trained research assistant. We corrected missing or incorrect records while listening to the recording to ensure the accuracy of the transcription. Data analysis was performed simultaneously with data collection. We re-read the data to familiarize ourselves with it. Thereafter, we generated the codes, which were pithy labels achieved through capturing both a sematic and conceptual reading of the data regarding meaningful words, phrases, sentences, and paragraphs in the transcripts. To search for themes, codes were classified into similar meaning units by comparing their similarities and differences. Subsequently, for reviewing themes, we checked the themes in relation to both the coded extracts and the full data-set, and defined and named them by writing a detailed analysis and identifying the essence of each theme. Finally, we wrote a weaving analytic narrative and contextualized it.

All analyses were performed manually by our research team. We shared and discussed our experiences and opinions regarding data collection and analysis via e-mail. 3 researchers possess prior knowledge of various types of cancer patients, and are experts in conducting qualitative research.

\section{Ethical Consideration}

This study was approved by the institutional ethics committee of the university (1044396-201707-HR-116-01). We obtained written consent from the participants, after explaining the purpose and procedure of the study, and the advantages and disadvantages of participating. The researchers also informed the participants in advance that they were free to withdraw their participation at any time, and that the interviews would be recorded, coded, and numbered to safeguard their privacy and confidentiality. They were also informed that the data would be used for research purposes only and the recordings and manuscripts would be kept on a single locked computer. Monetary incentives were provided to the participants.

\section{Ensuring Rigor in Research}

For ensuring rigor in this study, we applied the criteria proposed by Sandelowski. ${ }^{10)}$ The data of this study reveals the actual experiences of the participants, and we believe that the reliability of the data is secure. Specifically, the interviews were recorded and transcribed verbatim. We tried to ensure the accuracy of the transcriptions by comparing the recordings with the transcriptions. We also identified the adequacy of citations to support themes derived from the data. The participants' experiences were described and interpreted based on the derived themes. To ensure fittingness, natural interviews were conducted to reveal specific experiences of CRF. We further considered the demographic factors and stage diversity of the study participants. Auditability was secured by following a qualitative thematic analysis process so that readers could understand the process well and other researchers could track the research process despite changes over time. We read the manuscript multiples times with theoretical sensitivity to the data, and clearly described the analytical procedures for deriving initial codes, sub-themes, and themes. To ensure confirmability, our bias on breast cancer survivors and cancer-related fatigue was 
bracketed and eliminated in the process of data collection and analysis. We also tried to maintain neutrality throughout the research process.

\section{RESULTS}

The participants' fatigue was described as a shadow that accompanied them from the moment they were diagnosed with cancer, and which did not leave their side even for a second. Sometimes they perceived the shadow as long and dark, and other times as so pale that it did not seem to be there, but was nevertheless always present.
The shadowy experience of fatigue accompanied the participants in their daily lives. This initial disturbance evolved over time into social disorders, including difficulty in fulfilling roles and alienation in relationships with acquaintances and family. The themes and subthemes derived from the analysis are presented in Table 2.

\section{Traces of fighting cancer}

The participants accepted the feeling of fatigue as a sign of fighting cancer, despite planned treatment. After completion of treatment and returning to daily life, the fatigue was experienced as a scar of the

Table 2. Thematic Analysis of Experiences of Cancer-related Fatigue in Breast Cancer Survivors

\begin{tabular}{|c|c|c|}
\hline Meaning unit & Sub-theme & Theme \\
\hline $\begin{array}{l}\text { - It is a different tiredness than before diagnosis } \\
\text { - I didn't feel like I was in hormone therapy } \\
\text { - Fatigue persists even when treatment is over } \\
\text { - I want to live as a normal person } \\
\text { - Continuous fatigue causes fear of cancer recurrence } \\
\text { - I expected to improve over time, but I am tired after five years }\end{array}$ & Marker of cancer patients & Traces of fighting cancer \\
\hline $\begin{array}{l}\text { - If I tell a medical staff that I feel heavy, they say you are undergoing } \\
\text { menopause because of chemotherapy } \\
\text { - There is disappointment due to the indifference of the medical staff } \\
\text { - It's hard to tell a doctor }\end{array}$ & $\begin{array}{l}\text { Negligence of the medical } \\
\text { staff regarding the } \\
\text { symptoms of fatigue }\end{array}$ & \\
\hline $\begin{array}{l}\text { - I take a nap and it is difficult to get up } \\
\text { - Iying on the bed } \\
\text { - I both exercise and work, so I am tired, and so I quit exercising and } \\
\text { only work now } \\
\text { - I'm tired so l'm incapable of showering }\end{array}$ & Shadows all around & $\begin{array}{l}\text { Inseparable part of } \\
\text { the self }\end{array}$ \\
\hline $\begin{array}{l}\text { - If I make it hard around, I'Il fall apart } \\
\text { - I feel like I'm losing my mind } \\
\text { - I feel like I'm going to sink under the ground } \\
\text { - I feel like my body is melting down }\end{array}$ & The body being dragged & \\
\hline $\begin{array}{l}\text { - I have no energy for a couple } \\
\text { - My husband's demands are annoying }\end{array}$ & $\begin{array}{l}\text { Bothersome sexual } \\
\text { relationships }\end{array}$ & Difficulty in daily life \\
\hline $\begin{array}{l}\text { - It is difficult to prepare for children's meals and replace them with cus- } \\
\text { tom } \\
\text { - I can't let the children go to school } \\
\text { - Prepare rice hard, lie down again, and wake up when it is time to eat } \\
\text { again } \\
\text { - It's hard to stand in front of the sink }\end{array}$ & $\begin{array}{l}\text { The role of the mother being } \\
\text { diminished }\end{array}$ & \\
\hline $\begin{array}{l}\text { - I'm tired of going out for a while } \\
\text { - Can't go shopping or join gatherings } \\
\text { - I don't go out with promises } \\
\text { - I can hardly go out at night } \\
\text { - Appreciate and return early so that the meeting will not be harmed }\end{array}$ & $\begin{array}{l}\text { Social activities becoming } \\
\text { passive }\end{array}$ & \\
\hline $\begin{array}{l}\text { - When my body reacts, I lie down } \\
\text { - I'll take a break tomorrow } \\
\text { - Go home early and rest }\end{array}$ & Yellow traffic light & Body's signals for care \\
\hline $\begin{array}{l}\text { - The information is obtained through the patient meeting } \\
\text { - I listen to hospital health lectures } \\
\text { - I exercise regularly every day } \\
\text { - I go to the mountains, even if you have difficulty breathing in fresh air } \\
\text { - I changed from family first to I first } \\
\text { - I try to live happily } \\
\text { - I try not to be stressed } \\
\text { - I go to bed before } 11 \text { to get good sleep }\end{array}$ & Struggle for recovery & \\
\hline
\end{tabular}


disease that convinced the participants to still be identified as cancer patients.

\section{1) Marker of cancer patients}

The fatigue experienced by the participants was different from that experienced by the general public. It was also very different from the fatigue the participants had experienced in the past. The feeling that the whole body sank to the bottom without being resolved by resting was taken as a unique symptom of fatigue in cancer patients. Some participants shared that they would be surprised to find themselves dozing off while talking to friends, and expressed concern and worry regarding being able to ever live a normal life.

"Even if there are funny things, it's never really $100 \%$ fun. Thoughts about my condition are always underlying. That's how it is. That's why sometimes when I laugh like this, I think, what the heck, can I laugh like this? I sometimes feel that way."(Participant 6)

None of the treatment methods were easy for the participants. Treatment methods, such as surgery, chemotherapy, and radiation therapy, exhausted their mind and body, and made them feel lifeless and fatigued. The hair grows back again and the cloudy skin color is restored, marking the end of a long struggle with cancer and the beginning of a healthy self. However, patients still experience difficulties due to fatigue.

"I thought it would get better over time. Sometimes when I'm very tired, things really bother me. At that time, I reluctantly keep working but ah! it's very hard. I just think about this often...” (Participant 3)

\section{2) Negligence of the medical staff regarding the symptoms of fatigue}

The fatigue experienced by the participants seemed natural and insignificant to the medical staff. The participants hesitate to ask or consult healthcare professionals about their symptoms of fatigue. At the start of chemotherapy, they were informed that CRF could arise anytime due to the treatment itself, hence, they could not ask the medical staff any questions. "Doctors say that it's all natural. So, what question can you ask?", enquired a participant. The participants expressed disappointment regarding the insensitivity of the medical staff toward the significance of their fatigue, and in searching for alternative solutions.

"If I say I feel too heavy and tired when I meet the professor, he/ she says it's because of medication, menopause, and so on and so forth. I don't know the cause, what is the reason?"(Participant 10)

\section{Inseparable part of the self}

Fatigue was not merely a simple symptom, instead it became a part of the participants' selves and the daily life that cancer had assigned them. Most participants felt that fatigue results from the shock and emotional instability associated with being diagnosed with cancer, that later turns into extreme physical fatigue due to medical treatment, and continues as a chronic shortage of energy after radiotherapy. They further disclosed that the perception of a "tired person" seemed to be imprinted in their minds and those around them when referring to themselves.

\section{1) Shadows all around}

The participants understood fatigue as a negative energy field resulting from cancer that surrounded their entire lives. They experienced fatigue as a clinging shadow-present all day and in all areas of their house and life.

"I felt that way. If things around me make something hard on me, I'm tired like it'll all fall ... just release me and let me go. I feel that way."(Participant 2)

\section{2) The body being dragged}

They felt that fatigue caused their body to feel as if it was lying down and being dragged on the floor. Their body and mind seemed to be dragged by a force that was pulling them down, and whose source they could not identify. Despite trying to move and reorganize their mind to overcome this feeling of being dragged, they experienced a feeling of sadness and tiredness. The participants expressed worry and frustration regarding this feeling of tiredness that persisted even after the completion of treatment.

"I haven't done anything much, today,' I say to myself. I really didn't do anything today but I feel my body is just tired. Have I ever been so mentally stressed that even though I'd like to take 
care of myself, my stress stops me from doing so? The mental stress is just anger for no reason, and I don't think it has anything to do with my heavy body. But the body is always heavy, and the mind is never light."(Participant 12)

\section{Difficulty in daily life}

The participants had trouble conducting activities of daily living due to CRF. Daily activities, which are usually taken for granted, felt broken, and displaced by CRF. The participants assess their physical condition in the morning, determine all the activities including household chores that need to be performed, and distinguish between the work that needs to be undertaken and the work that can be postponed. The participants were ambivalent about feeling sorry for their families or those around them because of their inability to perform their roles in their daily life, and about wanting to understand themselves.

\section{1) Bothersome sexual relationships}

Married participants in their 40s and 50s shared that fatigue-related changes in daily activities were the first to appear in their sexual relationships. After surgery and chemotherapy, their body recovered, and their husband's need for physical intimacy resurfaced, however, it seemed too bothersome to them. They first noticed their fatigue when they realized their avoidance of sexual relationships, that they had enjoyed before.

"I don't know if I can tell you this, but you know in a sexual relationship, I think it's the most annoying amongst all annoying things. So, my husband looks pitiful and a little bit bad, but my priority is myself. It couldn't be that way yet, from my side. I think that's the hardest time."(Participant 2)

\section{2) The role of the mother being diminished}

Almost all the participants were housewives who spent a lot of time on housework and parenting, and they spent the most important part of their daily lives caring for their children. However, fatigue hindered their ability to care for their children. The participants experienced tiredness and difficulty in lifting and carrying their children, in preparing breakfast, and packing lunch, that left them feeling resentful and diminished. In this situation, the participants spent all their energy in attempting to fill the void in the child's life, by asking a caregiver or a close neighbor to care for the child.

"I have to take care of the kids, I have to take my kids to school, but I feel like I can't. Then I send them alone or with someone else, or something like that. And it seems hard to take care of the kids' meals, so I don't make any side dishes and just order them to eat what is on the table."(Participant 1)

\section{3) Social activities becoming passive}

The fatigue that continued after completion of treatment resulted in a lack of confidence in meeting friends, and participating in small groups and religious activities. They felt embarrassed every time they dozed off during these meetings, and no longer wanted to be perceived as a patient. Whether it was meeting people from outside, working in government offices, or shopping, daily activities became difficult and exhausting for them. Since most participants knew that they had to perform their daily activities, they adjusted the number and intensity of outdoor activities as per their daily physical condition.

"It's okay to do one thing a day like going to a department store or going to a supermarket. But now when I have two or three things like this and then I go here and there, I feel extremely tired. So, after all that, when I finally get home, I try to rest the next day without going out."(Participant 4)

\section{Body's signals for care}

Participants learned positive healthcare tips due to their experience of fatigue. The participants interpreted the meaning of fatigue in their own ways. "My body is trying to tell me to rest," "warning me not to be greedy," and "indicators of daily activities," were accepted as signals of fatigue. Moreover, coping with fatigue reduced its interference in daily life. Most participants walked regularly to exercise, and practiced a religious life or mind by eating healthy and overcoming psychological fatigue.

\section{1) Yellow traffic light}

Fatigue, as an alarm for the body to rest, warned participants of a shift in attention and behavior. Participants accepted the level of fatigue as an indicator of work and rest. Body and mind fatigue served as a traffic light for healthcare needs, such as "now you must rest," and "you cannot do the next thing unless you rest now," and so on. Participants 
interpreted fatigue positively as a pause to better handle their body, and they adjusted the amount of activity as per their energy.

"If I feel tired, I lie down anyway. 'Cause when the body won't follow, how do you cook food and work the washing machine? I' $m$ so tired and then my body loses strength. I just want to move, but I'm going to bed because I feel weak. I must lie down for 30 minutes or an hour. And then I feel a little bit better, and oh, I drink a glass of water or eat a piece of fruit..."(Participant 10)

\section{2) Struggle for recovery}

When all participants experienced tiredness for the first-time during treatment, they managed to take care of the fatigue because they had experienced it before when they were healthy. They shared that they would actively search for ways to effectively manage their fatigue. They exercised regularly, followed a healthy diet, and practiced healthy ways to manage stress due to a need to recover fully. In this process, however, the lack of communication with healthcare professionals led to confusion among the participants about whom to consult regarding symptoms of fatigue. Most of the participants discussed ways of overcoming fatigue with fellow patients, and expressed an apprehension in discussing symptoms of fatigue with the medical staff.

"When I go to a laughter therapy center or something like that, I am told that I am happy and thankful. If I see just the slightest thing (maybe I am too old now), I like seeing it so much. Just makes me feel good to see the sky, or the mountains, and some water, to see clean water. Good to see fish, and people meeting each other. Being invited to any lecture would be appreciated." (Participant 7)

\section{DISCUSSION}

In this study, CRF in breast cancer patients was identified as a shadowy companion. Since the participants were so tired of fatigue being a significant part of their lives, they felt as if they were being dragged down by their physical condition, and thus experienced obstacles in their daily life. The experience of fatigue reported by arthritis patients, ${ }^{11)}$ under the theme of a vicious cycle of unpredictable symptoms were found to correspond to the findings of this study. Breast cancer patients under 50 years of age experienced more severe
CRF than patients over 50 years of age, which may be due to a worse prognosis due to age, and the more number of roles the younger patients are required to fulfill within their family, at work, and in society. ${ }^{12)}$ A deeper understanding of the association between agerelated fatigue and social role performance among breast cancer survivors may prove helpful.

Our findings confirmed that sustained symptoms of fatigue are perceived by participants as part of the disease process that does not end with signs of cancer but causes secondary anxiety about cancer recurrence. CRF in breast cancer survivors is greater than the fatigue experienced by general fatigue patients, and the uncertainty of CRF suggests that it can be easily translated and expanded into disease uncertainty. ${ }^{13)}$ Henshall and colleagues stated that since the fear of cancer recurrence is incompatible with the formation of an identity of a cancer survivor, cancer patients may be reluctant to identify as survivors. ${ }^{14)}$ Therefore, it is necessary to identify how cancer survivors who have completed treatment understand normalcy in the social context. $^{13)}$

In addition, participants expressed the need to be understood by their family or acquaintances, but showed a passive attitude and ambivalent feelings toward interpersonal relationships that they did not want to harm. Consistent with past findings, ${ }^{13)}$ our findings also suggest that the participants did not want their family and friends to worry about their symptoms of fatigue, but they also felt sorry that they could not understand their predicament. These results reflect the influence of an individual's social roles, identities, and interactions with others on the emotional and cognitive expressions of CRF. Therefore, support and encouragement from family and friends may help cancer survivors in rebuilding normalcy by practicing self-care after treatment. Thus, a normal recovery over time may be possible, depending on factors, such as social support, disease stage, economic condition, and workplace. ${ }^{14)}$ However, with regards to fatigue symptoms and the language used to express these symptoms, chronic fatigue syndrome and CRF may be indistinguishable. ${ }^{15)}$ For family members or healthcare professionals to understand CRF, the linguistic expression of fatigue-related symptoms in cancer survivors needs to be identified and compared with that of chronic fatigue syndrome.

As cancer patients tend to resolve the symptoms of fatigue by themselves without consulting the medical staff, there is insufficient understanding of CRF in the clinical setting. ${ }^{15)}$ Analysis also revealed 
a hesitation among the participants to talk about CRF with healthcare professionals who took fatigue for granted. Patients with chronic fatigue syndrome resort to oriental medicine to alleviate symptoms of fatigue because healthcare professionals do not pay proper attention to their symptoms of fatigue. ${ }^{16)}$ Additionally, there is a difference in awareness of CRF between healthcare professionals and patients.

A study that conducted discourse analysis reported that patients are reluctant to discuss symptoms of fatigue with healthcare professionals because CRF has no symptoms, no cause, and no treatment. Moreover, CRF is excluded from the discourse of the disease and medical professionals seldom investigate it. Since cancer is considered highest in the hierarchy of all diseases, CRF is masked by cancer. ${ }^{15)}$ Therefore, it is necessary for medical practitioners to pay attention to CRF and sympathize with cancer survivors, while checking their tendency to be overwhelmed with the treatment of cancer itself and focusing on treatment alone.

In addition, studies on the differences in awareness of CRF between healthcare professionals and cancer patients have shown that compared to oncologists, cancer patients recognize many more effects of CRF in their daily lives. While the oncologists are more aware of pain during chemotherapy, the patients are more aware of fatigue, suggesting the need to gain a deeper understanding of symptoms of fatigue while treating tumors. ${ }^{17)}$ Therefore, accurate assessment is needed for effective management of CRF. Fatigue, however, lacks objectivity because it relies on self-report, ${ }^{5)}$ thus giving rise to problems with assessment of fatigue. CRF assessment tools should be developed in line with evidence-based guidelines. However, since there are currently no guidelines based on systematic assessments, it is necessary to develop guidelines that allow for inter-disciplinary access considering social, cognitive, and motivating factors. ${ }^{18)}$

National Comprehensive Cancer Network (NCCN) guidelines suggest methods of energy conservation and conversion therapy. ${ }^{19)}$ Patients with CRF, after treatment, should attempt to carry out physical activity, yoga, rehabilitation, physical therapy, cognitive behavioral therapy, or medication to treat sleep disorders, distress, and anemia. The participants of this study practiced exercises, such as hiking and walking, and living a religious life to manage psychological fatigue, thus implementing the guidelines of NCCN at an individual level in terms of physical activity, rehabilitation, or physical therapy.

Consistent with the findings of Corbett and colleagues, ${ }^{13)}$ cancer survivors in this study also embraced fatigue, exercise, seeking social support, thinking positively, resting, and performing activities adequately to control the exacerbation of fatigue symptoms. When participants woke up in the morning, they assessed their physical condition, determined their overall degree of activity, and distinguished between what they needed to do and what they could postpone. Primdahl and colleagues suggested that the amount of activity at home and at work should be well planned according to the patient's ability. ${ }^{11)}$

Since well-managed CRF can improve quality of life and enhance the willingness of the patients to accept future treatment, CRF should be a major concern for healthcare professionals, ${ }^{20)}$ but the response or intervention toward CRF tends to be insufficient. The self-regulatory model is known to help patients express their symptoms and illnesses and evaluate them considering the physical and mental characteristics of cancer survivors. ${ }^{13)}$ Since the self-regulation program is thought to be a useful model for the normalization of cancer survivors, there is a need to improve the self-efficacy and quality of life of breast cancer survivors by developing and applying self-regulation programs aimed at managing CRF among breast cancer survivors.

\section{CONCLUSIONS}

Breast cancer survivors often worry that fatigue could be the starting point for cancer recurrence, since they suffer from symptoms of fatigue in everyday life despite completion of treatment. Moreover, breast cancer survivors attempt to cope with fatigue by responding sensitively to the healthcare warnings conveyed by their bodies.

Further research and a follow-up study are required to support our findings. A study based on conversation analysis is needed to gain a deeper understanding of the communication between healthcare professionals and breast cancer survivors about CRF. Further, there is a need to develop and evaluate interventions programs aimed at managing cancer-related fatigue in breast cancer survivors. There is also a need to compare the differences in the expression of symptoms of fatigue between patients with chronic fatigue syndrome and breast cancer survivors.

\section{ORCID}

Son, Haeng-Mi orcid.org/0000-0002-5165-4536

Park, Eun Young orcid.org/0000-0003-1356-6487

Kim, Eun-Jeong orcid.org/0000-0001-7668-331X 


\section{REFERENCES}

1. Davis LE, Bubis LD, Mahar AL, Li, Sussman J, Moody L, et al. Patientreported symptoms after breast cancer diagnosis and treatment: a retrospective cohort study. Eur J Cancer. 2018;101:1-11.

2. Fabi A, Falcicchio C, Giannarelli D, Maggi G, Cognetti F, Pugliese P. The course of cancer related fatigue up to ten years in early breast cancer patients: what impact in clinical practice? Breast. 2017;34:44-52.

3. Kaur N, Gupta A, Sharma AK, Jain A. Survivorship issues as determinants of quality of life after breast cancer treatment: report from a limited resource setting. Breast. 2018;41:120-6

4. Hwang SS, Chang VT, Rue M, Kasimis B. Multidimensional independent predictors of cancer-related fatigue. J Pain Symptom Manage. 2003;26:604-14.

5. Gerber LH. Cancer-related fatigue: persistent, pervasive, and problematic. Phys Med Rehabil Clin N Am. 2017;28:65-88.

6. Williams LA, Bohac C, Hunter S, Cella D. Patient and health care provider perceptions of cancer-related fatigue and pain. Support Care Cancer. 2016;24:4357-63

7. Nail LM. Fatigue in patients with cancer. Oncol Nurs Forum. 2002;29:537-46.

8. Yang YH. Comparison of fatigue and quality of life in the women with breast cancer according to two different treatment modalities: chemotherapy vs radiotherapy. J Korean Acad Soc Nurs Educ. 2003;9:244-52

9. Clarke V, Braun V. Teaching thematic analysis: overcoming challenges and developing strategies for effective learning. Psychologist. 2013; 26:120-3

10. Sandelowski M. The problem of rigor in qualitative research. ANS Adv Nurs Sci. 1986;8:27-37.

11. Primdahl J, Hegelund, Lorenzen AG, Loeppenthin K, Dures E, AppeIEsbensen B. The Experience of people with rheumatoid arthritis living with fatigue: a qualitative metasynthesis. BMJ Open. 2019

12. Swen M, Mann A, Paxton RJ, Dean LT. Do cancer-related fatigue and physical activity vary by age for black women with a history of breast cancer? Prev Chronic Dis. 2017;14:E122.

13. Corbett T, Groarke A, Walsh JC, McGuire BE. Cancer-related fatigue in post-treatment cancer survivors: application of the common sense model of illness representations. BMC Cancer. 2016;16:919.

14. Henshall C, Greenfield S, Gale N. The role of self-management practices as mechanisms for re-establishing normality in cancer survivors. Qual Health Res. 2017;27:520-33

15. Pertl MM, Quigley J, Hevey D. 'I'm not complaining because I'm alive’: barriers to the emergence of a discourse of cancer-related fatigue. Psychol Health. 2014;29:141-61

16. Son HM, Park EY, Kim DH, Kim E, Shin MS, Kim TH. Experiences with, perceptions of and attitudes towards traditional Korean medicine (TKM) in patients with chronic fatigue: a qualitative, one-on-one, indepth interview study. BMJ Open. 2015;5:e06178.

17. Salmon M, Blanchin M, Rotonda C,Guillemin F, Sebille V. Identifying patterns of sdapation in breast cancer patients with cancer-related fatigue using response shift analyses at subgroup level. Cancer Medicine.2017:6;2562-2575.

18. Pearson EJ, Morris ME, McKinstry CE. Cancer related fatigue: implementing guidelines for optimal management. BMC Health Serv Res. 2017;17:496.

19. National Comprehensive Cancer Network. 2019 Cancer-related fatigue [Internet]. Available from:

https://www.nccn.org/professionals/physician_gls/pdf/fatigue.pdf [Accessed May 2, 2019].

20. Yeh C, Wang L. Potential pathophysiological mechanism of cancer-related fatigue and current management. Formos J Surg. 2014;47:173-82 